\title{
Effectiveness of Anger Control Training on Resiliency, Happiness and General Health in Veterans' Sons
}

\section{ART ICLE INF O}

\section{Article Type}

Original Research

\section{Authors}

Hosseini M.H. ${ }^{* 1} P h D$

Khavari S. ${ }^{1} M S C$

Bozorgi Kasgari M. ${ }^{2} M D$

Shahmoradi Pileh Rood M. ${ }^{3} M S c$

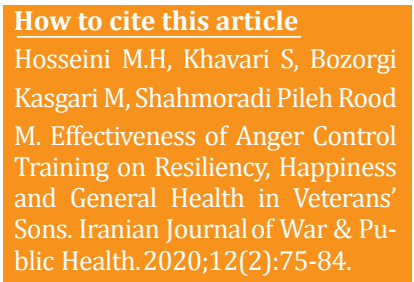

${ }^{1}$ Department of Business Management, Payame Noor University, Tehran, Iran

${ }^{2} J a n b a z a n$ Medical and Engineering Research Center (JMERC), Tehran, Iran

${ }^{3}$ Department of Humanities, Faculty of Psychology and Educational Sciences, Islamshahr University, Tehran, Iran

\section{*Correspondence}

Address: Department of Business Management, Payame Noor University, Nakhl Street, Tehran, Iran. Postal Code: 193954697.

Phone: -

Fax: +98 (21) 88916533

ri_hosseini@yahoo.com

\section{Article History}

Received: March 09, 2020

Accepted: May 14, 2020

ePublished: June 17, 2020

\section{A B S T R A C T}

Aims The stress of war is not limited to the wartime period, but also triggers chronic and acute reactions after the war, characterized by psychological and physical damage. The aim of this study was to determine the effectiveness of anger management training on resilience, happiness and general health of veterans' sons.

Material \& Methods The research was quasi-experimental with pretest and posttest with case and control groups. The number of samples required for this study was 30 male students of the veteran child of the second high school of Shahed school in Kerman in 2018, in which 15 people were randomly assigned to the case group and 15 to the control group. Anger control training was conducted for 12 sessions in the case group. To collect the required data in both pre-test and post-test stages, 4 trait-anger expression questionnaires (STAXI-2), Conor-Davidson Resilience Questionnaire (C-DRS), Patterson Happiness Questionnaire and General Health Questionnaire were used. The collected data were analyzed using analysis of covariance and SPSS 23 software.

Findings There was a significant difference between case and control groups in terms of resilience, happiness and general health scores after presenting the independent variable (anger management training) $(\mathrm{p}<0.001)$, so that the effect of anger control on resilience variable $60 \%$, Happiness $41 \%$ and general health $65 \%$.

Conclusion Anger management training is effective in increasing resilience, happiness and general health of veterans' sons.

\section{Keywords Anger Training; Resilience; Happiness; General Health}

\section{I T A T I O N L I N K S}

1] The comparison of internet addiction ... [2] Comparison of resilience, self-differentiation ... [3] Role of secondary post-traumatic stress ... [4] Surveying the impact of cognitive -behavioral ... [5] The effectiveness of group training of problem ... [6] Effectiveness of Social-Emotional Skills ... [7] Effectiveness of social skills training ... [8] Resilience as a theoretical basis for ... [9] The effectiveness of training forgiveness ... [10] The relation of locus of control, Anger ... [11] Anger expression, coping, and substance ... [12] General mental health and aggression ... [13] The impact of anger control training ... [14] The relationship between empowerment ... [15] The Relationship between psychological ... [16] Effectiveness of resilience training on anger ... [17] The effectiveness of reality therapy on ... [18] Cutaneous and ocular late complications ... [19] Effectiveness of positive psychology interventions ... [20] Examining the relationships between ... [21] Effectiveness of resiliency training on ... [22] Development of a new resilience scale ... [23] Orientation to happiness and life satisfaction ... [24] Effectiveness of positive group pschotherapy ... [25] The normalization of general health ... [26] Validity and Reliability of General ... [27] Selfreflection, a pursuit of ... [28] Aggression management trainging for ... [29] Resikience training: A Pilot study of a mindfulness ... [30] Investigating the effectiveness of resilient ... [31] Internet use, social engagement and health ... [32] Surveying the relationship between psychological ... [33] Adolscent resilience: A framework ... [34] Resilience in development ... [35] Be happy: The role of resilience between ... [36] Lifestyle choices and mental health: A longitudinal ... [37] Efficacy of anger management training on ... [38] Effectiveness of anger management and ... [39] Study of relation between life quality ... 
خسارتهاى بهجامانده در سالهاى اخير بىنظير بود و باعث شد شأد

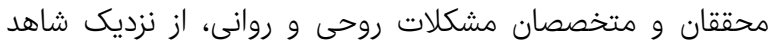
فشارهاى روانى-عصبى ناشى از آن در ميان بازماندكان و ونزان نزديكان

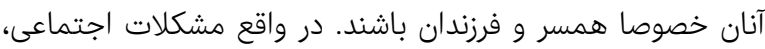

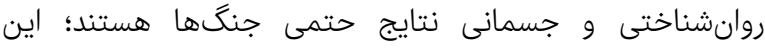

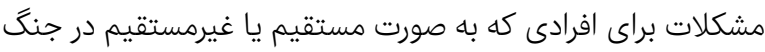

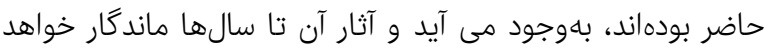

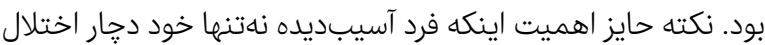

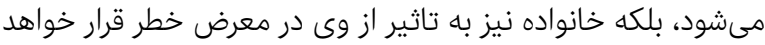

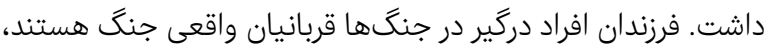

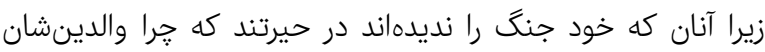

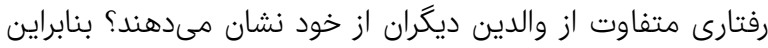

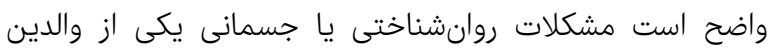

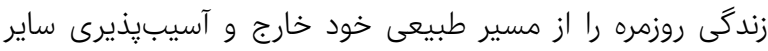

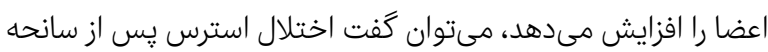

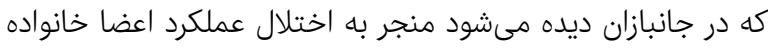

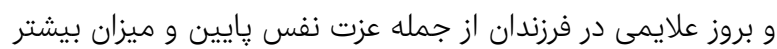

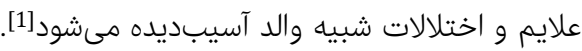

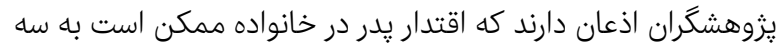

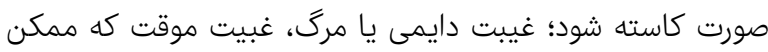

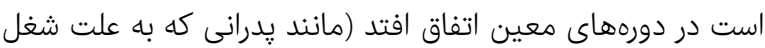
خود مجبور به مسافرت هستند) و يدرانى كه در خانه هستند ولى الى دانى

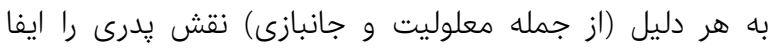

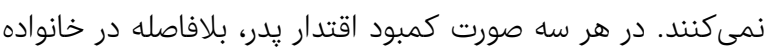

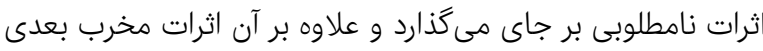

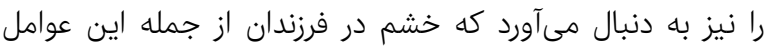

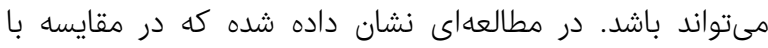

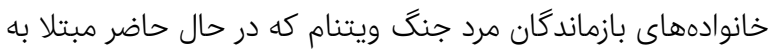

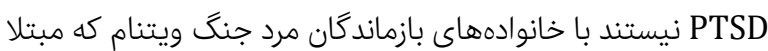
به PTSD هستند، سطوح بالاترى از مسايل شديد و عميق در انطباق خانوادگى و زناشويى، مهارتهاى والدى و رفتار خصمانه را نشان

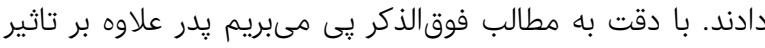

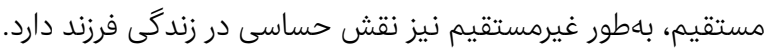

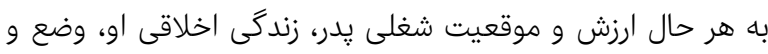

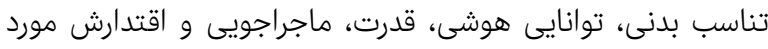

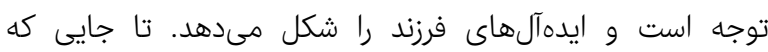

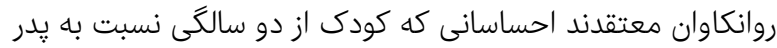

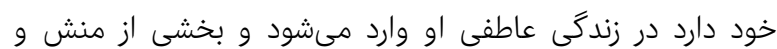

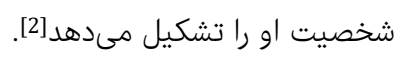

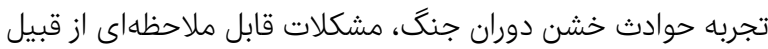

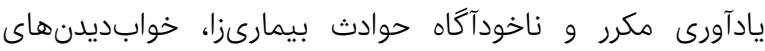
عودكننده در ارتباط با آن حوادث، بروز رفتار و احساسات آنات آنى جنانانكه

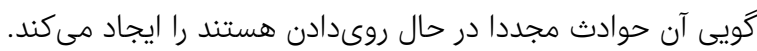

\section{اثربخشى آموزش كنترل خشم خمران بر تابآورى، شادكامى و سلامت عمومى در فرزندان ڤير

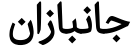

\author{
PhD ميرزا حسن حسينى \\ كروه مديريت بازركانى، دانشَاه بِيام نور، تهران، ايران \\ MSc Mحر خاورى مدريت بارناني" \\ كروه مديريت بازركانى، دانشَاه بِيام نور، تهران، ايران

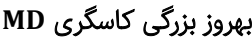

مركز تحقيقات مهندسى و علوم يزيكري يزشى جانبازان، تهران، ايران

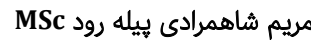

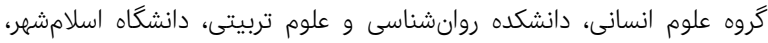

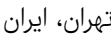

جكيده

اهداف: استرس ناشى از جنگ، فقط به دوران جنگ محدود نمى ماشود، بلكه يس

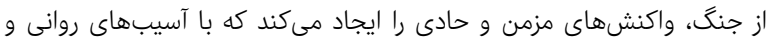

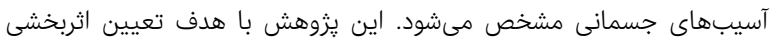

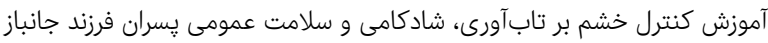

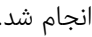

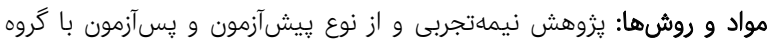

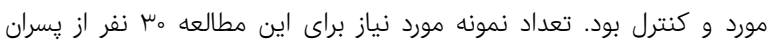

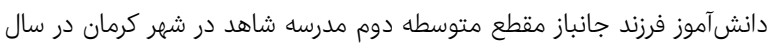

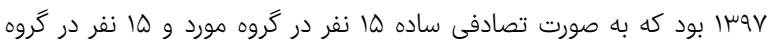

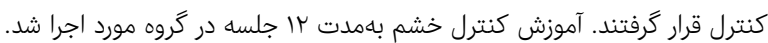

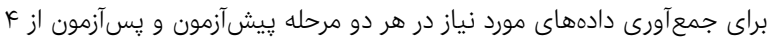

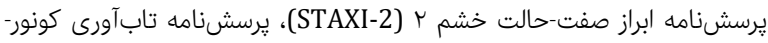

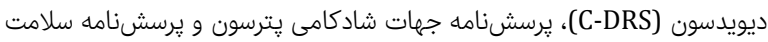

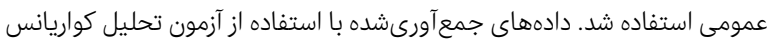

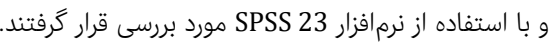

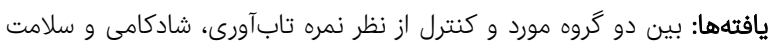

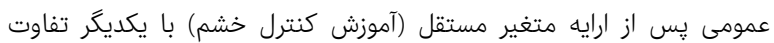

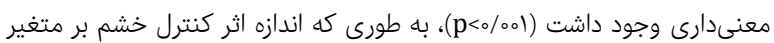

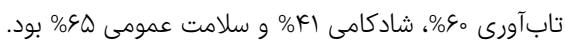

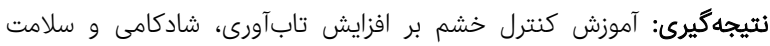

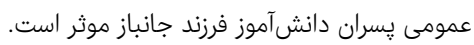

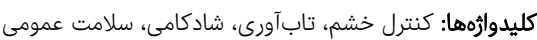

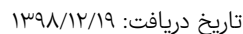

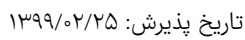

ri_hosseini@yahoo.com :نويسنده مسئول: بذائوش:

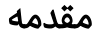

استرس ناشى از جنگ، فقط به دوران جنگَ محدود نمىشود، بلكه

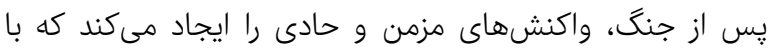

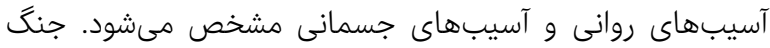

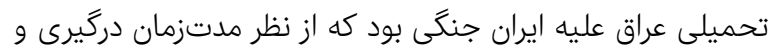




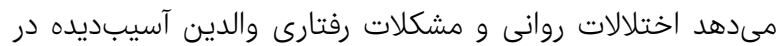
جنگ به دو صورت مستقيم و غيرمستقيم بر افكار و رفتار فرزندان

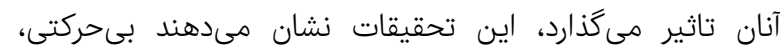

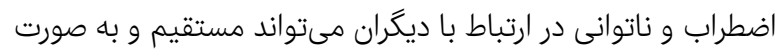

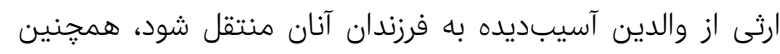

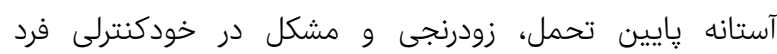

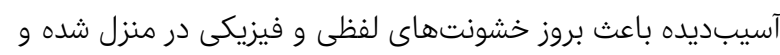

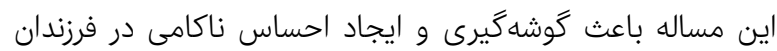

مى شود [3]. مرورى اينترنتى در پايگاههاى تحقيقاتى، مقالات و كتابهاى

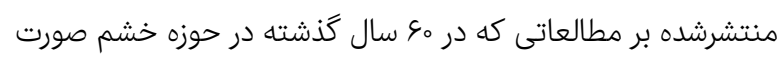

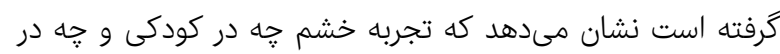
نوجوانى با مشكلات مهمى ارتباط دارد. خشم مفرط، كودكان و وهن

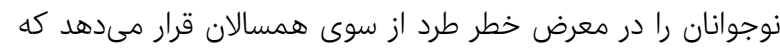

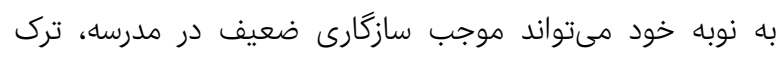

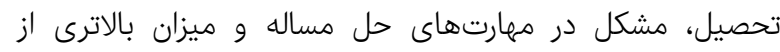

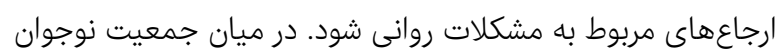

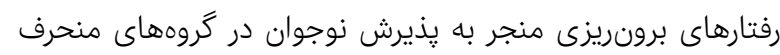

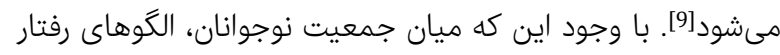

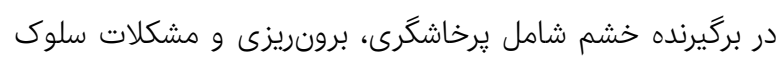

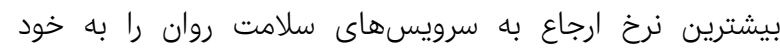

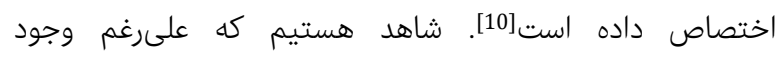
يزوهشهاى زياد در خصوص نقش اضطراب و افسردگى، نقش هُه

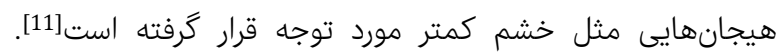

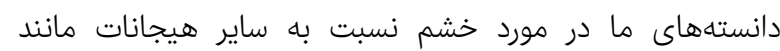

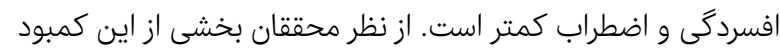

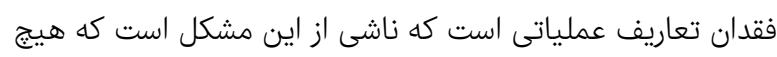

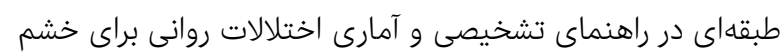

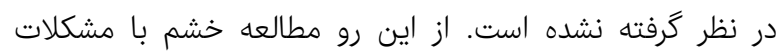

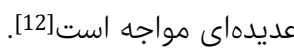
يثوهشگران اذعان دارند كه عوامل حمايتى همانند عوامل روانى-

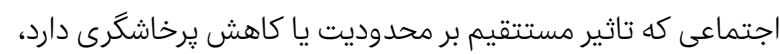

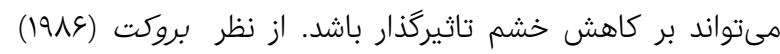

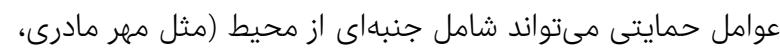

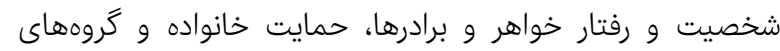

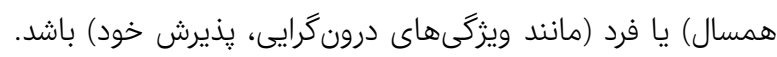

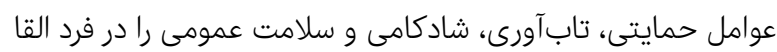
مى كنند [13]. برخى يُزوهشكران بيان كردهاند كه روانشناسان مثبتگرا متعهدند

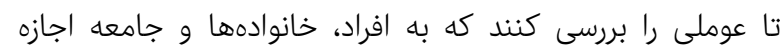

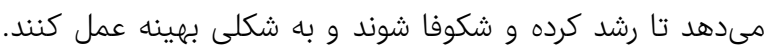
تابآورى نيز مولفهاى است كه در روانشناسى جايگاه ويزهاى دارد دارد.
تمامى عوامل، نهتنها مشكلاتى براى خود فرد بهوجود مىآورند، بلكه

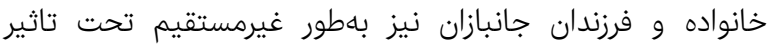

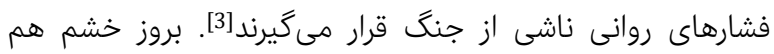
مىتواند از مشكلاتى باشد كه فرزندان جانبازان نيز به آن آن مبتلا شوند.

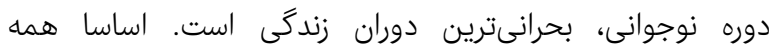

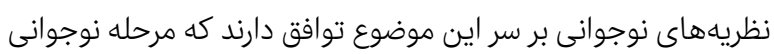

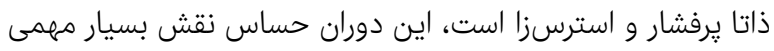

در شكلگيرى شخصيت و آينده فرد دارد[4].

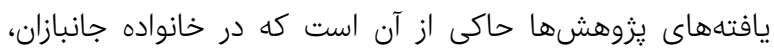

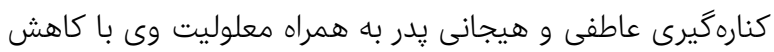

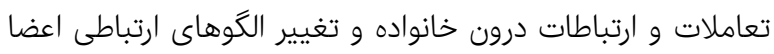

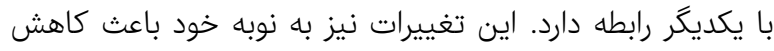
هوش هيجانى فرزندان جانباز به ويزه در مولفه بين فردى و نير نيز

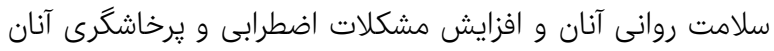

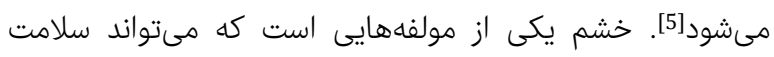
نوجوانان مخصوصا نوجوانان داراى يدر جانباز را تحت تاثير مواني قرار

دهد [6.6.

خشم، يك هيجان طبيعى است و از ويزگگهاى انطباقى فراوانى برخوردار است. آثار عدم مديريت خشم ان طيعيت اس ناراحتى فردى فراتر رفته

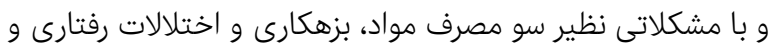

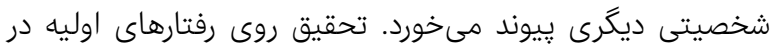

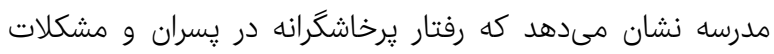

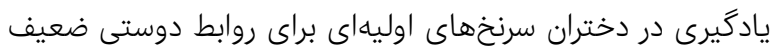

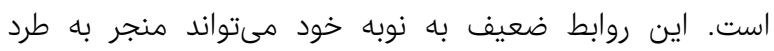

اجتماعى، تجارب منفى مدرسهاى و مشكلات رفتارى شود[7].

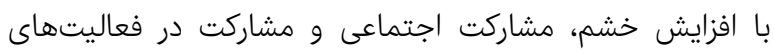

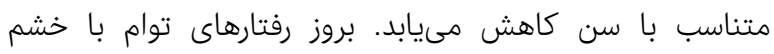

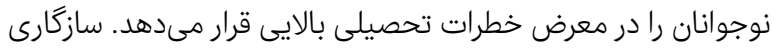

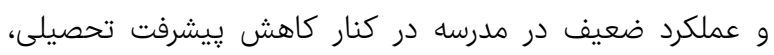

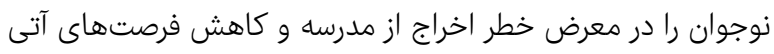

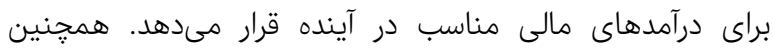
نوجوانانى كه در معرض خشم و خشونت قرار دارند در مقايسه با مانيا همسالان خود كه خشم و خشونت را به نيكى كنترل مى كنند، ميزان

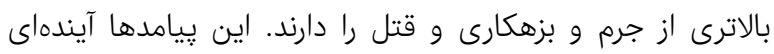

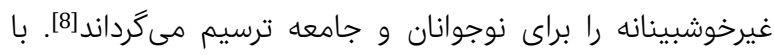

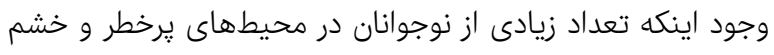

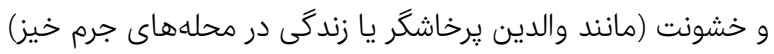

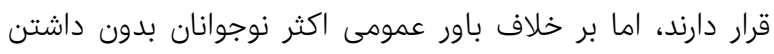

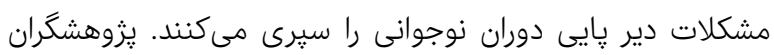

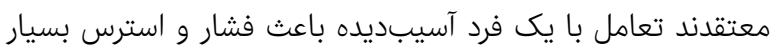

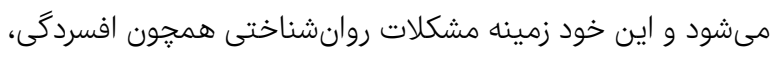

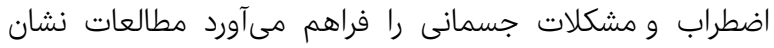




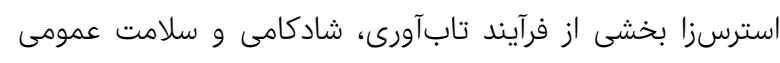

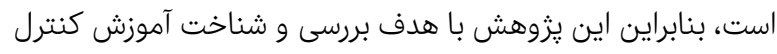

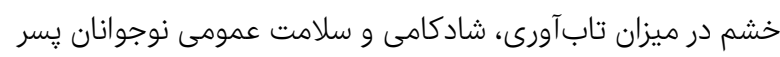

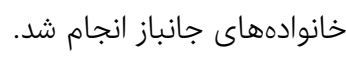

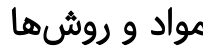

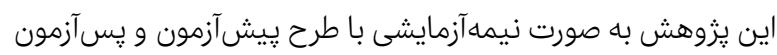

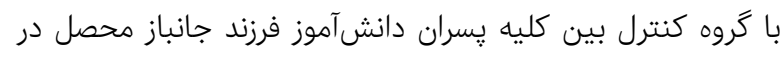

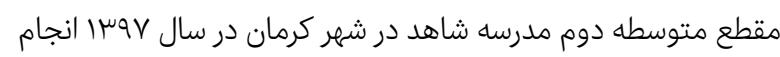

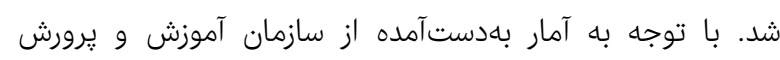

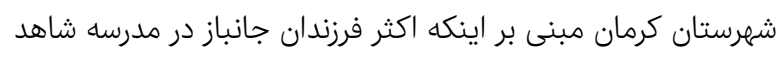

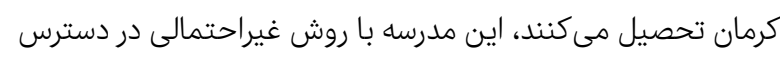

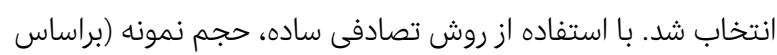

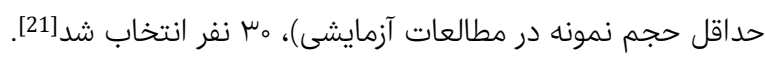

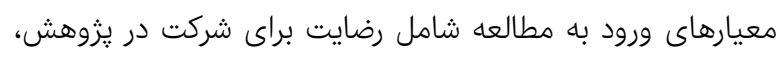

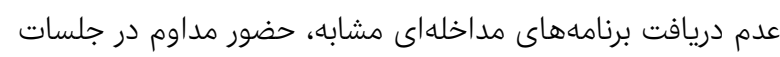

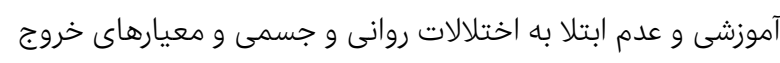

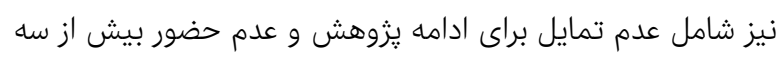

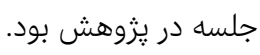

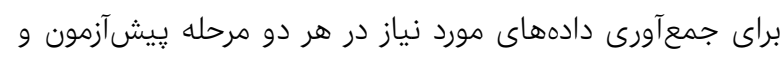

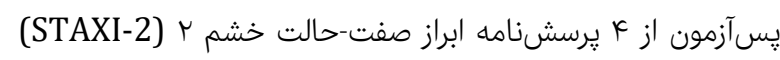

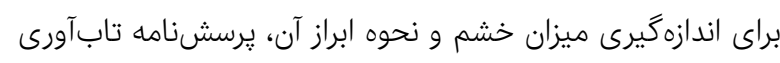

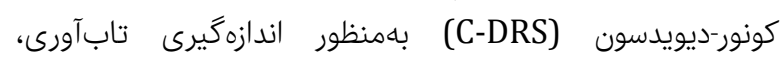
يرسشنامه جهات شادكامى يُترسون براى اندازمَّيرى شادكامى و و

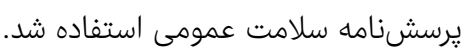

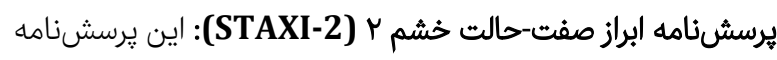

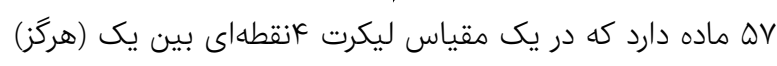

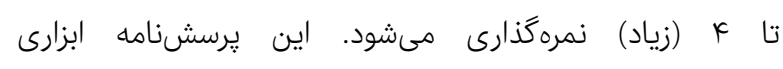

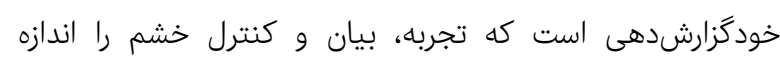

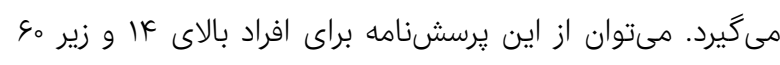

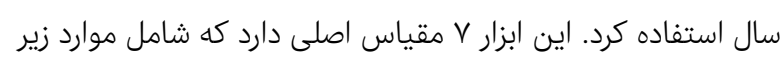

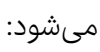

- خشم-حالت (S-Ang): 10 ماده شدت احساس خشم فرد را در زمانى معين اندازه مى خيرد.

- خشم-صفت (T-Ang): 10 ماده كرايش به تجربه و بيان خشم را

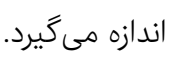

- بيان بيرونى خشم (AX-0): 1 ماده فراوانى خشم ابرازشده به سمت ديكران را اندازه مى خيرد.

- بيان درونى خشم (AX-I): 1 ماده فراوانى خشم سركوبشده را

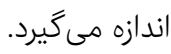

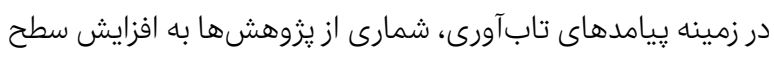

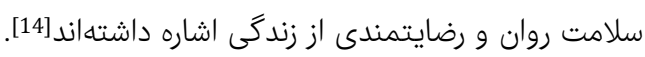

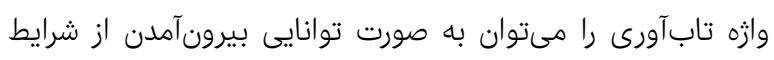

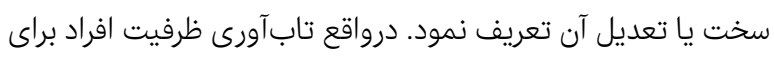

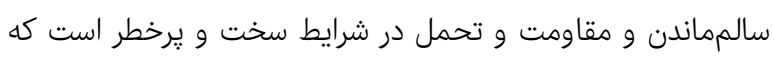

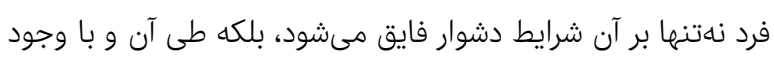

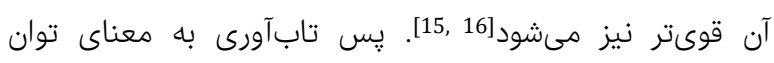

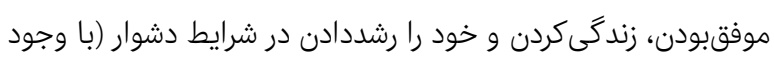

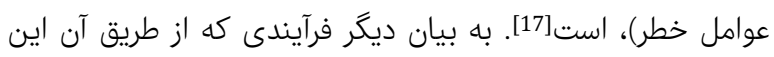

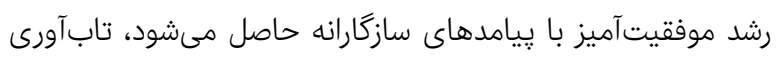

ناميده مىشود موفيت]

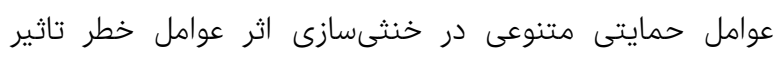

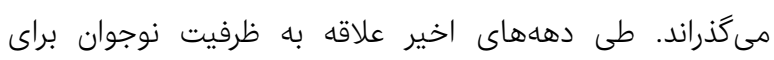

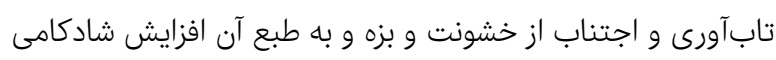

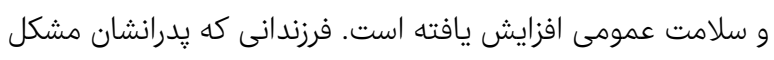

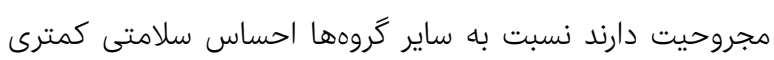

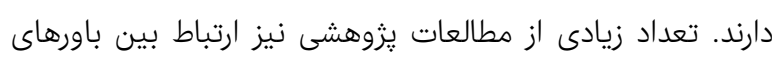

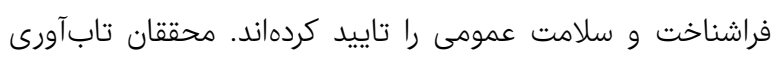

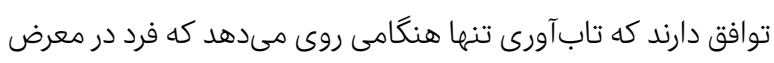

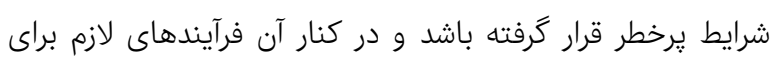

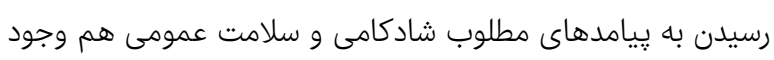

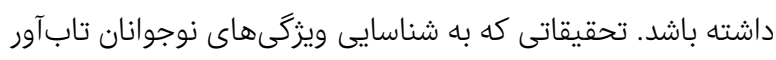

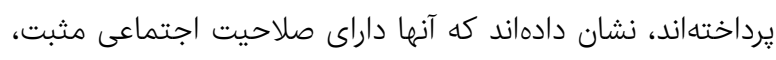

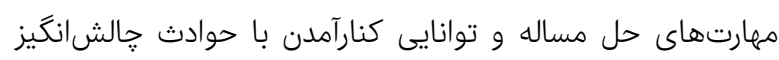

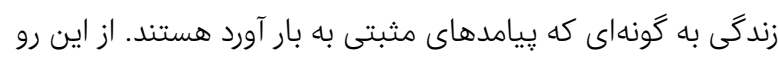

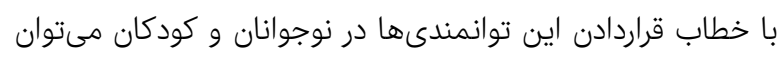

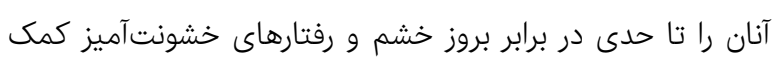

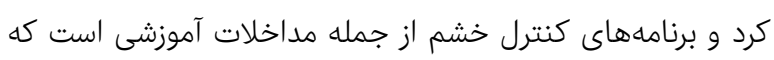

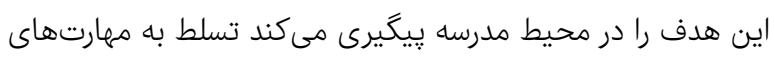

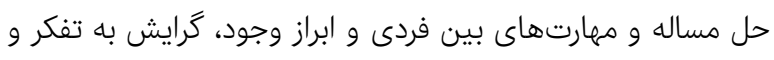

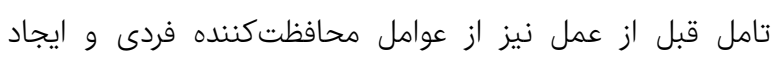
تاب آورى و جلوكيرى از خشم به ازيه حساب مى آيند [19.

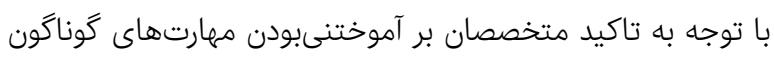

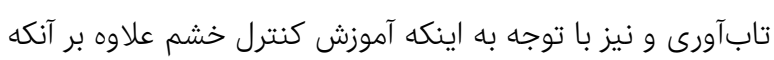

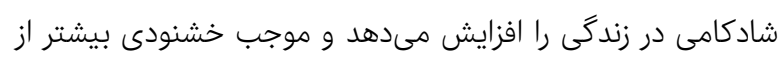

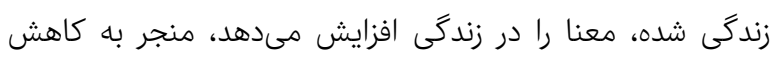

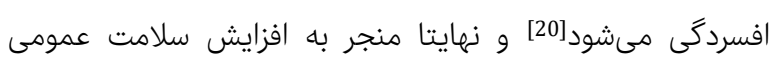

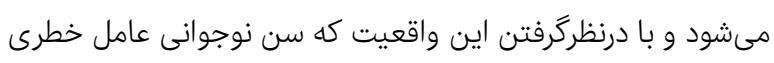

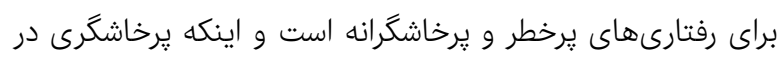

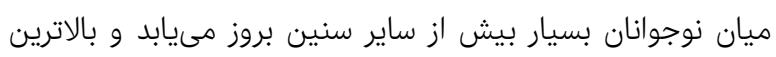

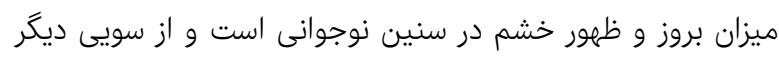
داشتن توانمندىهايى براى كنترل خشم و و برخورد موثر با عوامل 


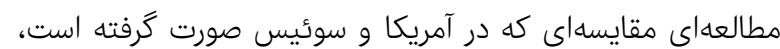

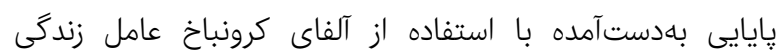

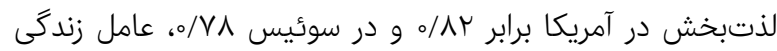

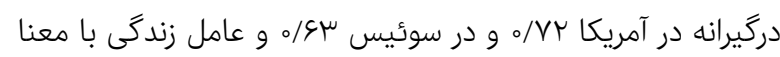

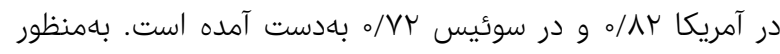

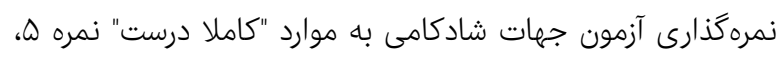

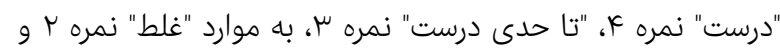

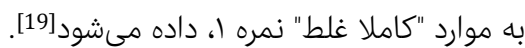

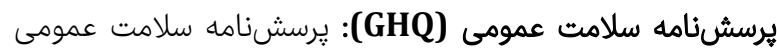
(Eneral Health Questinnire)

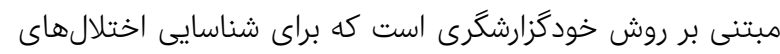

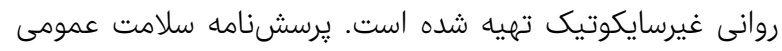

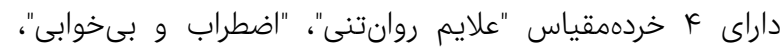

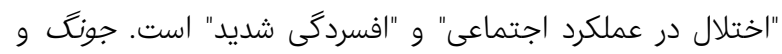

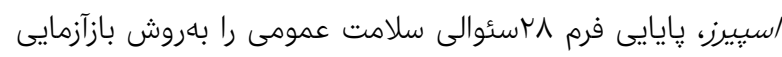

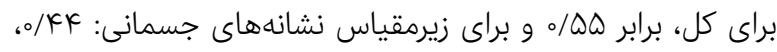

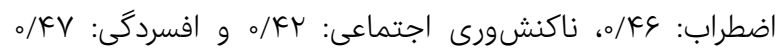

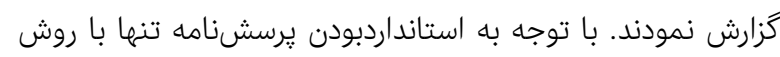

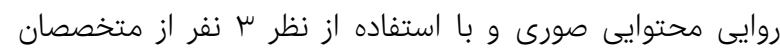

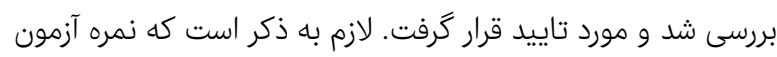

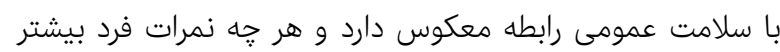
باشد، از سلامت عمومى كمترى برخوردار است [27-27.

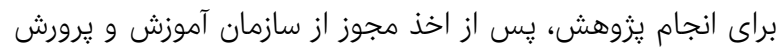

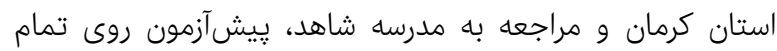

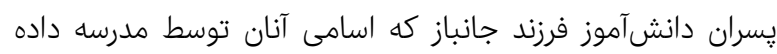

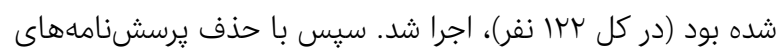

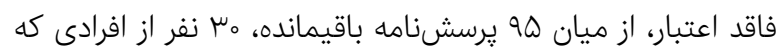

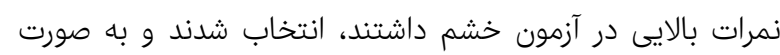

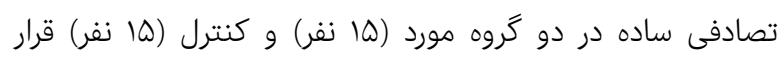

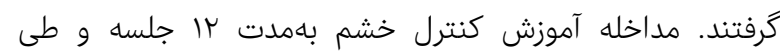

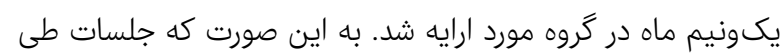

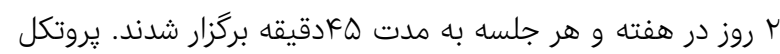

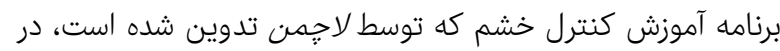

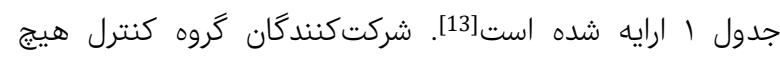

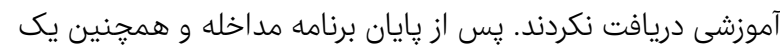

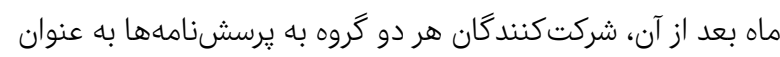

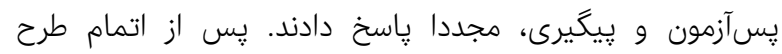

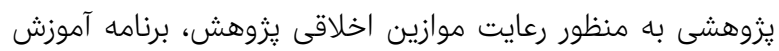

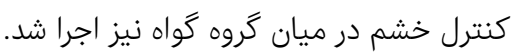

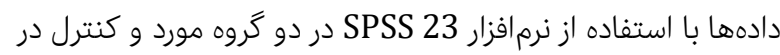

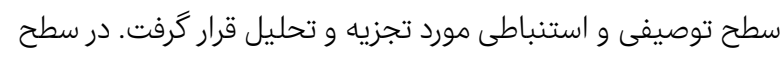
توصيفى، نمرات ميانكين و دامنه تغييرات محاسبه شد و در سطح

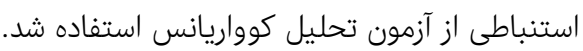

- كنترل بيرونى (AC-0): 1 ماده فراوانى تلاش براى كنترل بيان خشم را اندازه مى خيرد. - كنترل درونى خشم (AC-I) 1 ماده كه فراوانى تلاش براى كنترل خشم از طريق خود آرامسازى را اندازه مى خئيرد.

- شاخص ابراز خشم: شاخص كلى از فراوانى بيان خشم، سركوبى،

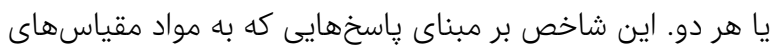
AX-O, AX-I, AC-O, AC-I

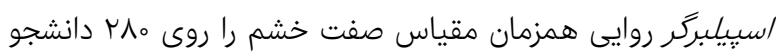

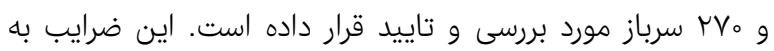

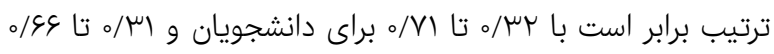

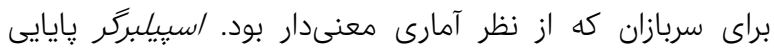

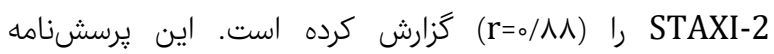
همبستخى مثبتى با ساير مقياسهاى خشم دارد[22]. در مطالعه

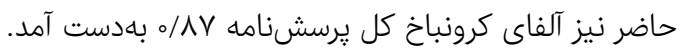

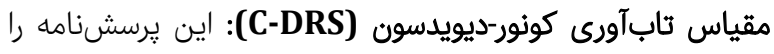

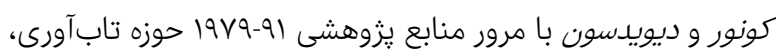

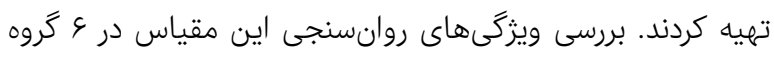

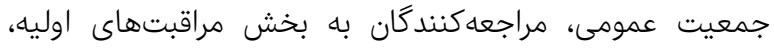

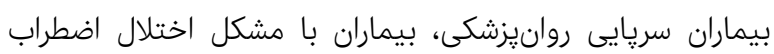

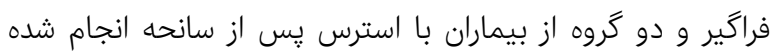

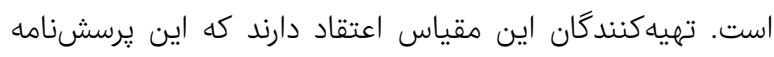

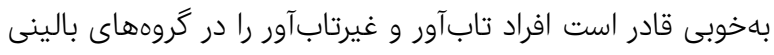

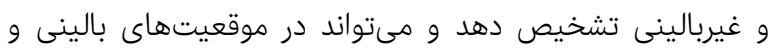

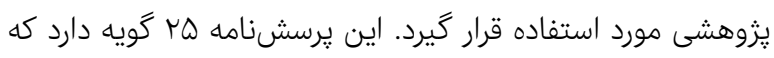

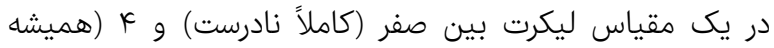

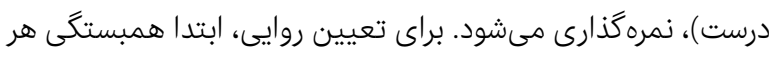

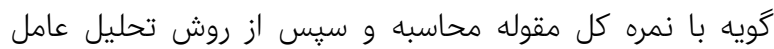

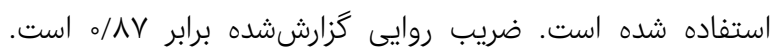

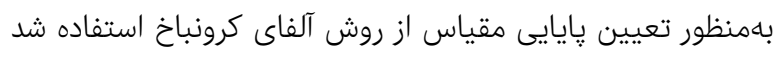

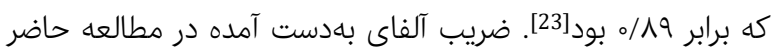

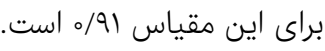

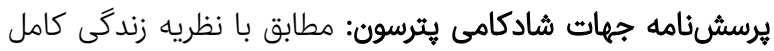

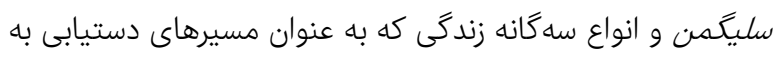

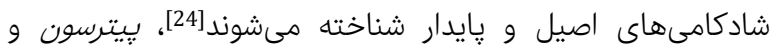

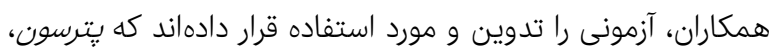
از آن تحت عنوان آزمون جهات شادكامى يا مسيرهاى شادكامى تدونى ياد

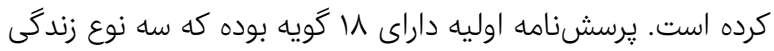

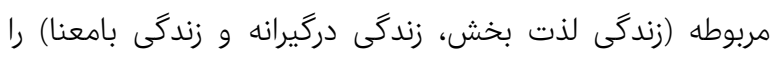

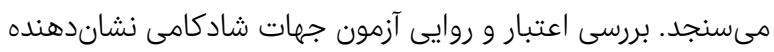

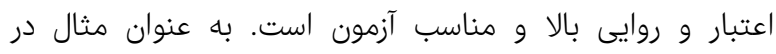




\begin{tabular}{|c|c|}
\hline شرح برنامه & جلسه \\
\hline 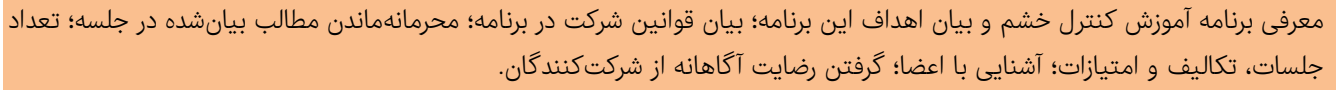 & اول \\
\hline 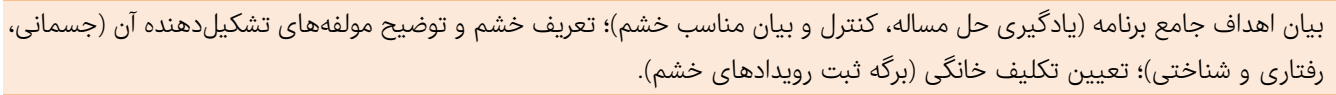 & دوم \\
\hline 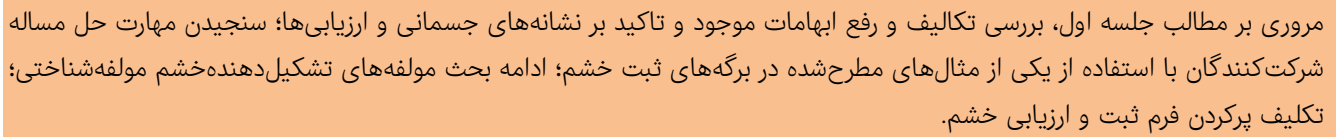 & سوم \\
\hline 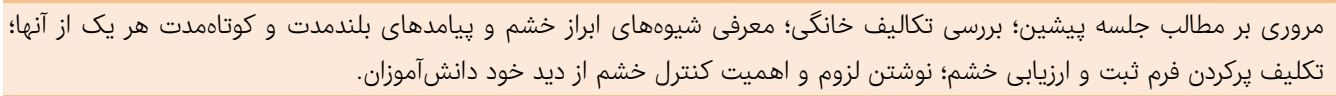 & جهارم \\
\hline 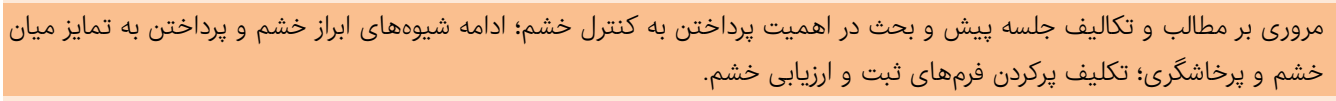 & هنجم \\
\hline 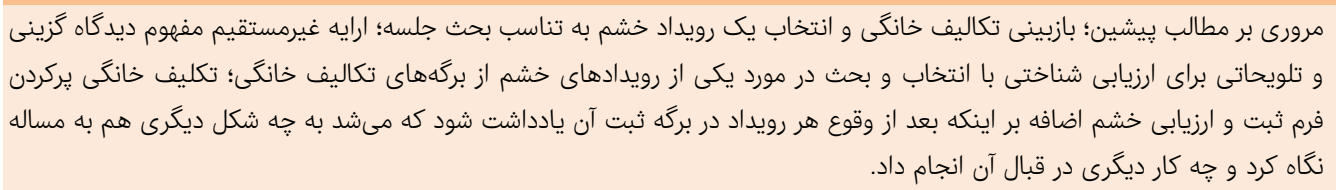 & ششم \\
\hline 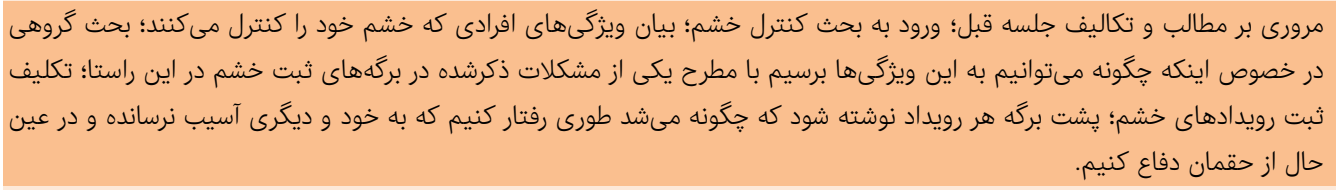 & هفتم \\
\hline 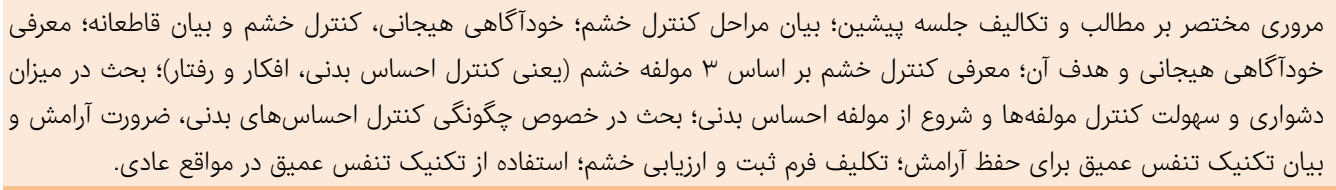 & هشتم \\
\hline 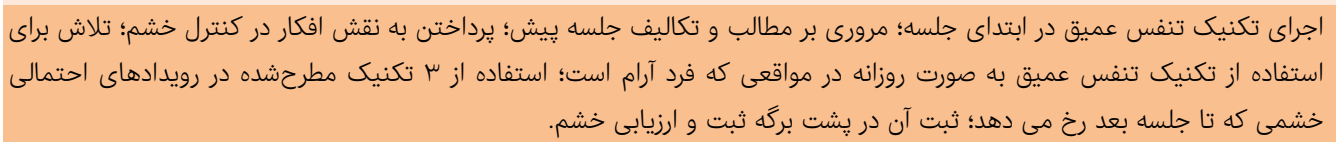 & نهم \\
\hline 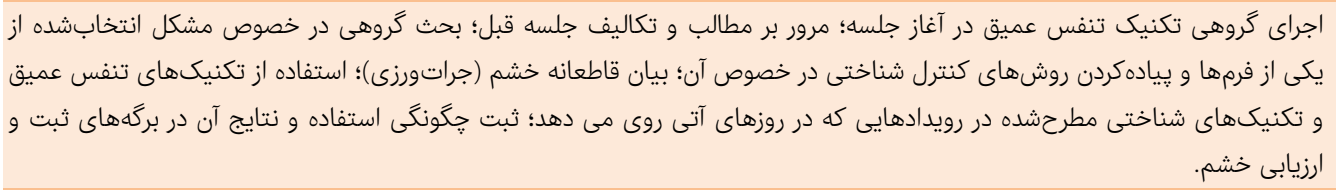 & دهم \\
\hline 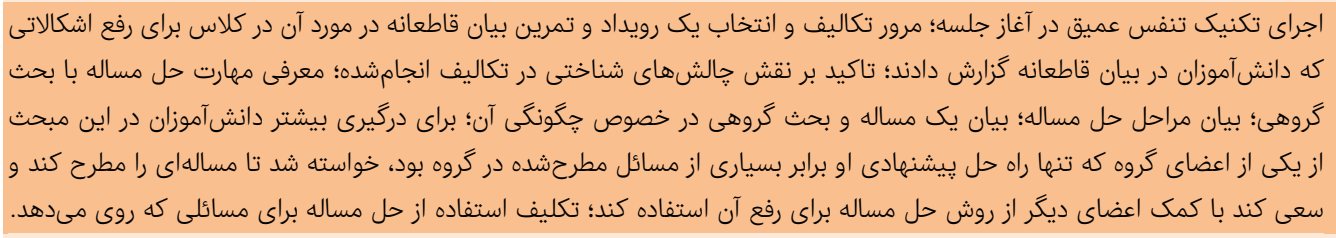 & يازدهم \\
\hline 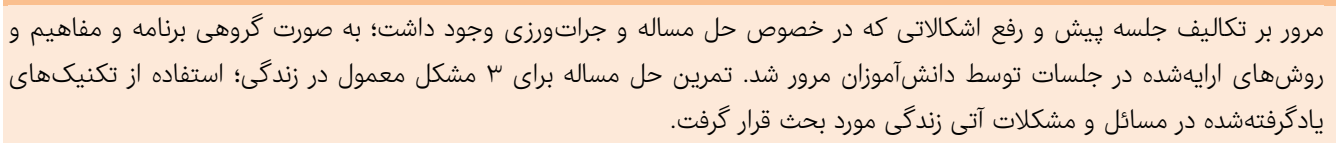 & دوازدهم \\
\hline
\end{tabular}

شاخص خشم در گروه كنترل از

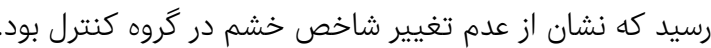
در ادامه و بهمنظور بررسى اثر آموزش خشم بر تابآورى، شادكامى

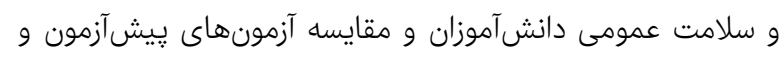
يسآزمون دو گروه، از آزمون تحليل كوواريانس (ANCOVA)

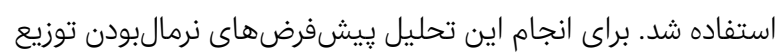

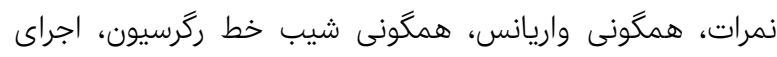

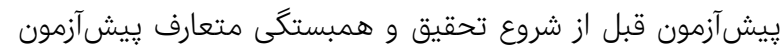
با هم بررسى شدند و همگى مورد تاييد قرار گرفتند.
اطلاعات جمعيتشناختى دانشآموزان شامل سن، رشته تحصيلى و يايه تحصيلى آنها در جدول r آمده است.

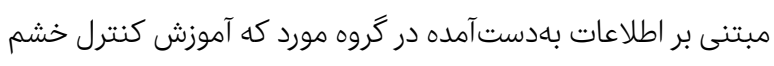

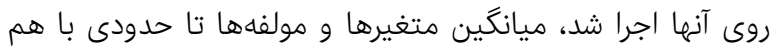

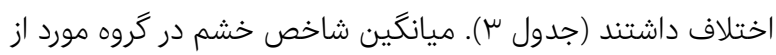
$0 V / T \pm F / \& 9$ در گروه كنترل كه آموزشهاى كنترل خشم روى آنها اجرا نشد، ميانكين متغيرها و مولفهها نزديك به هم بود و تغيير جندانى إنى نكرد. 
اثربخشى آموزش كنترل خشم بر تابآورى، شادكامى و سلامت عمومى در فرزندان يسر جانبازان

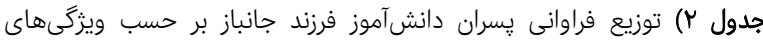

جمعيتشناختى جولى

\begin{tabular}{|c|c|c|}
\hline درود & تعداد & ويرگىهاى جمعيتشناختى \\
\hline & & رشته تحصيلى \\
\hline rV & $\wedge$ & رياضى فيزيك \\
\hline k。 & ir & علوم تجربى \\
\hline \multirow[t]{2}{*}{ س } & 10 & علوم انسانى \\
\hline & & سن (سال) \\
\hline 10 & $\mu$ & 10 \\
\hline$\Delta \mu$ & 18 & 18 \\
\hline w & 11 & IV \\
\hline & & يايه تحصيلى \\
\hline$r_{0}$ & $\varepsilon$ & دهم \\
\hline FV & if & يازدهم \\
\hline س & 10 & دوازدهم \\
\hline
\end{tabular}

نتايج نشان داد كه دو گروه از نظر نمره تابآورى، شادكامى و

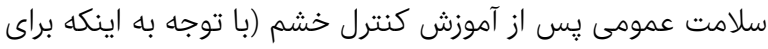

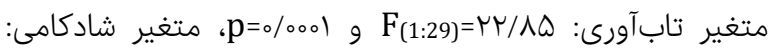

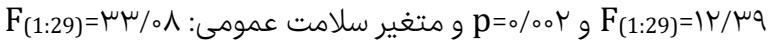

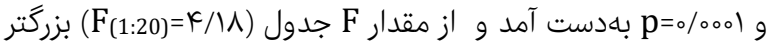

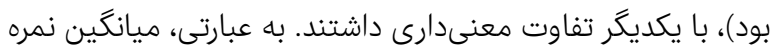

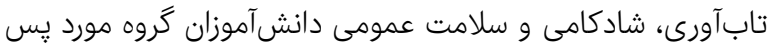

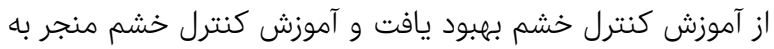

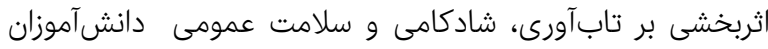

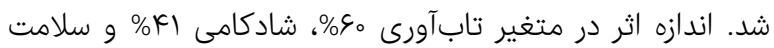

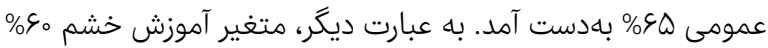

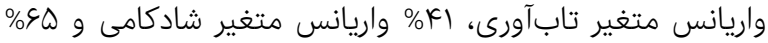
واريانس متغير سلامت عمومى را تبيين كرد.

جدول سا) نتايج ميانكَينهاى مربوط به متغيرهاى خشم در يسران دانشآموز فرزند جانباز در گروههاى مورد و كنترل (Q نفر در هر گروه)

\begin{tabular}{|c|c|c|c|c|}
\hline \multicolumn{2}{|c|}{ كروه كنترل } & \multicolumn{2}{|c|}{ گروه مورد } & \multirow{2}{*}{ عوامل } \\
\hline يس آزمون & هيش آزمون & يس آزمون & بيش آزمون & \\
\hline$\mu_{0} / 9 \varsigma \pm V / 9 Y$ & $\mu_{0} / \Delta V \pm \Lambda / V \mu$ & $\left.\mu_{0} / \Delta \Lambda \pm F / T\right)$ & $\mu F / \kappa \varepsilon \pm \Delta / r \Delta$ & خشم-حالت \\
\hline$K K / \neg K \pm \Delta / \Lambda \varepsilon$ & $r \Delta / \diamond V \pm \Delta / r q$ & $r \Delta / v K_{ \pm} \mu / I I$ & $r N / \Lambda \Lambda \pm \mu / K q$ & خشم-صفت \\
\hline$\Gamma \backslash / Y I \pm \mu / V q$ & $r M / r q \pm F / F F$ & 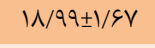 & $r \mu / \Delta S \pm r / \Lambda I$ & بيان بيرونى \\
\hline$r \mu / \mu \wedge \pm \psi / 01$ & $r Y / \Delta r \pm Y / \Lambda Q$ & $19 / .9 \pm 1 / 9 r$ & $r r / 9 V \pm r / F \mu$ & بيان درونى \\
\hline $\mid V / V I \pm 1 / 9 V$ & $\mid \Lambda / \Lambda \Lambda \pm r / \mu \zeta$ & $r I / K q \pm I / \wedge Q$ & $N / \Delta \xi_{ \pm} r / \mu_{0}$ & كنترل بيرونى \\
\hline $\mid V / \Lambda \Phi_{ \pm}+r / \mu \Delta$ & $|\Lambda /| \mid \pm r / 9 \Lambda$ & $r r / \circ \mu_{ \pm} r / \mu_{0}$ & $\mid \Lambda / \Delta \Lambda \pm 1 / V \Lambda$ & كنترل درونى \\
\hline$\Delta S / 01 \pm \Delta / \mu V$ & $\Delta \omega / \Delta ৭ \pm \varepsilon / \vee \Lambda$ & $\kappa \mu / V I \pm F / N Q$ & $\Delta V / r \pm K / \& Q$ & شاخص خشم \\
\hline $\mathrm{KY} / \Lambda \mathrm{V} \pm S / \Lambda \mathrm{V}$ & $K r / ৭ q \pm V / H G$ & $\triangle \Lambda / \varphi / \pm \Lambda / \Lambda \Lambda$ & $\kappa \mu / I V \pm \varepsilon / r \Delta$ & تابآورى \\
\hline$\Delta F / \Delta V \pm \varepsilon / \Delta \Lambda$ & $\Delta F / F r \pm q / \circ V$ & $\triangle Q / \circ \Lambda \pm \Delta / \Delta r$ & $\Delta \varepsilon / R Y \pm V / Q R$ & شادكامى \\
\hline$\mu_{0} / \Lambda \mu_{ \pm}|l / q|$ & $\mu r / 4 r \pm 18 / .9$ & $\|/\| \pm E / k \mu$ & $\mu F / V \Lambda \pm \mid Q / . \varphi$ & سلامت عمومى \\
\hline
\end{tabular}

تفاوتهاى معنىدار نشاندهنده نقش آموزش كنترل خشم در

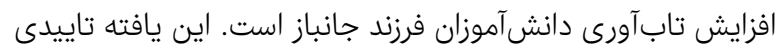

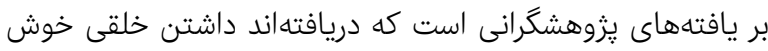

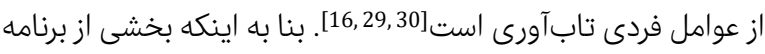
كنترل خشم، شامل آموزش مهارتهاى حل مساله و ابراز وجود

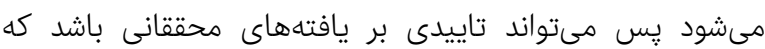

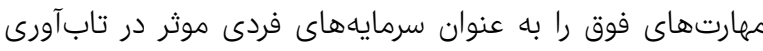

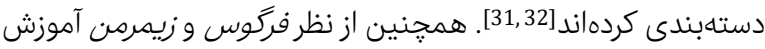

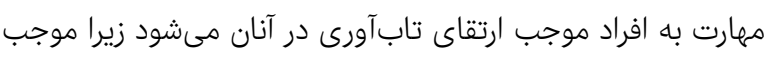
افزايش سرمايههاى آنان مىشود [34]. تابآورى طى زمان رشد مىكند. تابآورى نوعى مصونسازى در

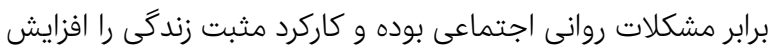

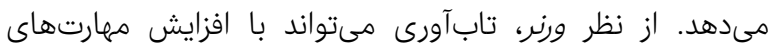

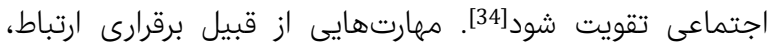
مهارت رهبرى، حل مساله، مديريت منابع، توانايى رفع موانعى كه

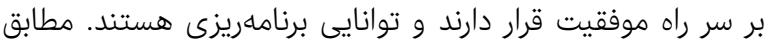

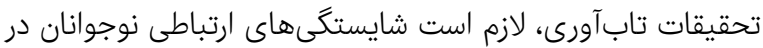

بحث

آموزش مولفههاى كنترل خشم به منزله راهبردى موثر كه مىتواند

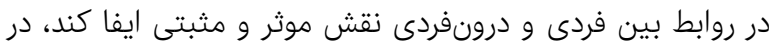
كشورهاى توسعه يافته گسترش بسيارى يافته و درو درون اين زمينه برنامههاى متعددى با رويكرد متفاوت، طراحى و اجرا شده است. بته

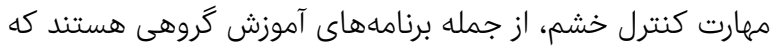

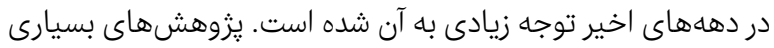

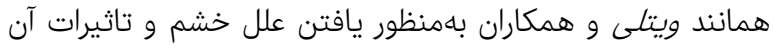

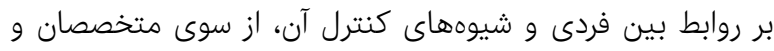

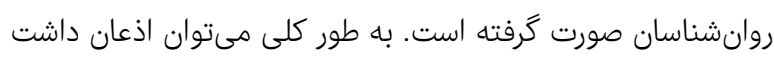

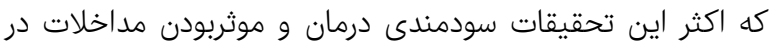

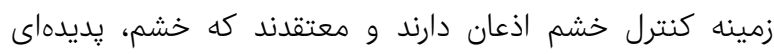

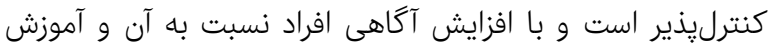
شيوهها و راهبردهاى موثر مىتوان خشم را كنترل و تعديدل كرد[28].

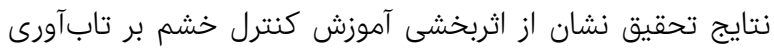

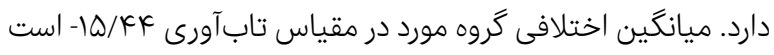

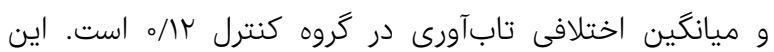


خشم به افراد در معرض آسيب و به خصوص فرزندان جانبازان الزامى

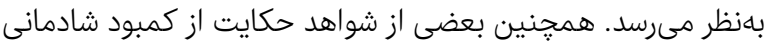

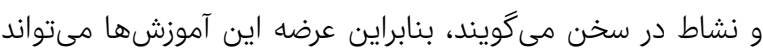

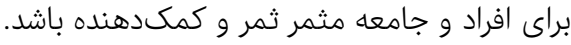

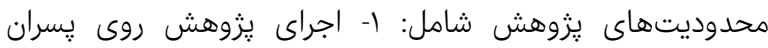

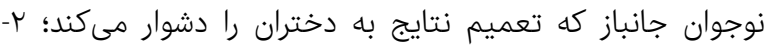

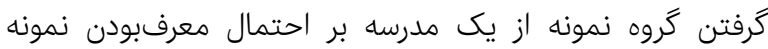

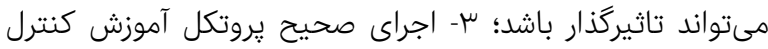

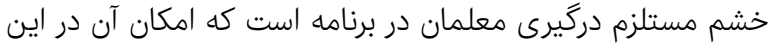

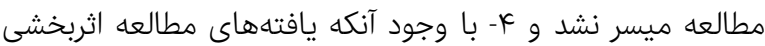
متغير مستقل را تاييد كرد، اما بررسى ثبات اين تاثير در طول زمان نياز به مطالعات بي ميخيرى دارد. از آنجا كه تشخيص بالينى نيازمند استفاده از ابزار و روشهاى دئهاري

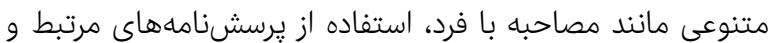
مشاهده فرد در موقعيت طبيعى در كنار استفاده از اطلاعات فردات

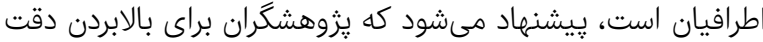
و ارزش تشخيص از ابزارهاى تشخيص مرتبط ديكرى نيز استفاده

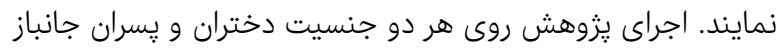

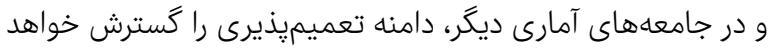

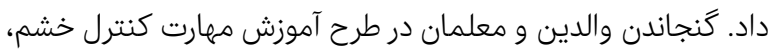

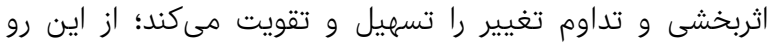

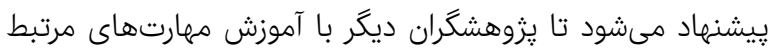
به والدين و معلمان، زمينه تقويت و استمرار تغييرات درمانى مورد

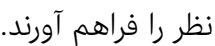

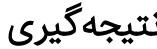

آموزش كنترل خشم بر افزايش تابآورى، شادكامى و سلامت عمومى يسران دانشآموز فرزند جانباز موثر است.

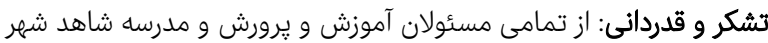

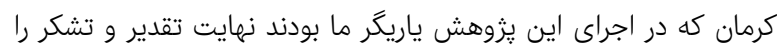

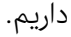
تاييديه اخلاقى: رضايت تمام افراد براى شركت در يزوهش اخذ شده است.

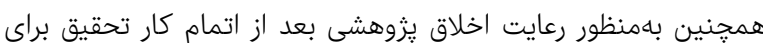

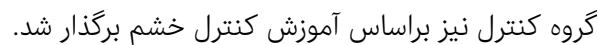
تعارض منافع: موردى از سوى نويسندكان بيان نشده آنتر است.

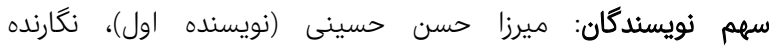

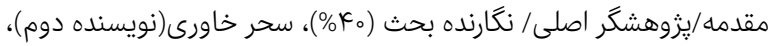

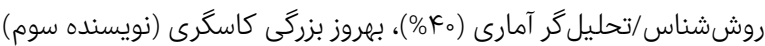

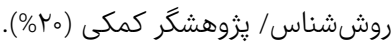

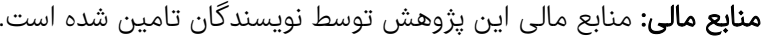

1- AllahKarami A. The comparison of internet addiction and the components of public health in the children of

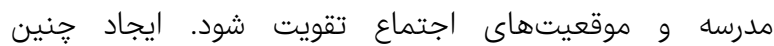

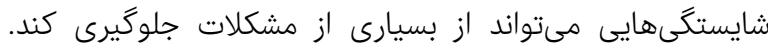

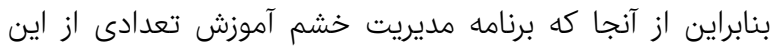

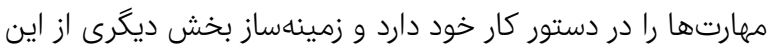

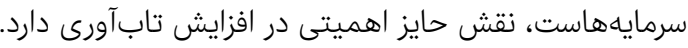

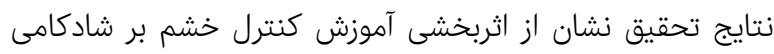

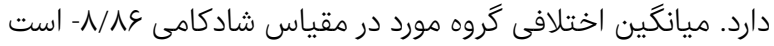

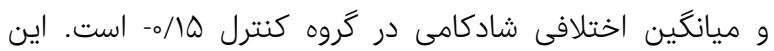

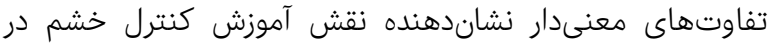

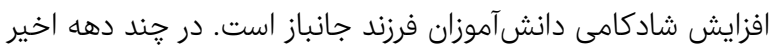

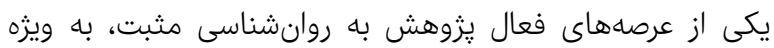

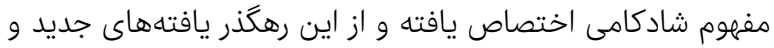

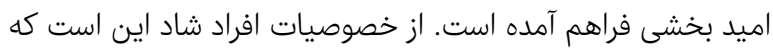

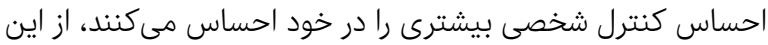

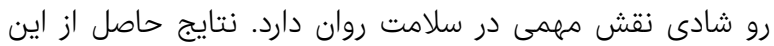

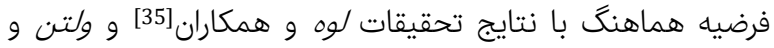
همكاران [36] است كه به طور كل بيان مىدارند كه كنترل خشم منجر به افزايش شادكامى مىشود. نتايج تحقيق نشان از اثربخشى آموزش كنترل خشم بر ساردام سلامت

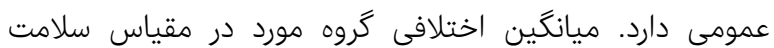

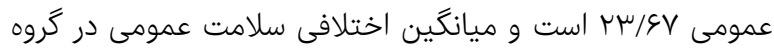

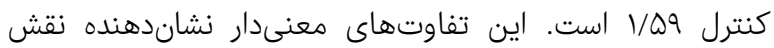
آموزش كنترل خشم در افزايش سلامت عمومى دانشآموزان فرزند

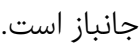
تحقيق حاضر هم راستا با تحقيق رسولى[13] و شكوهى يكتا و و همكاران[37] است و يافتهها دليلى بر مداخله دافله تربيتى-درمانى موثر و

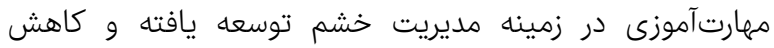

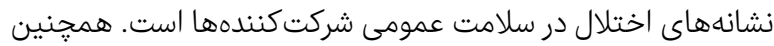
آموزش خودكنترلى از ميزان اضطراب افراد كاسته و موجب آنافي افزايش

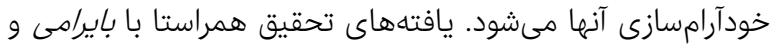

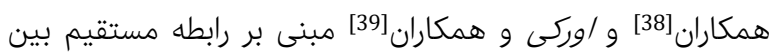

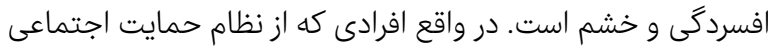

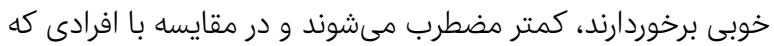

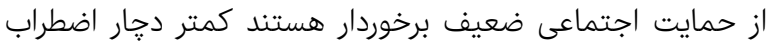

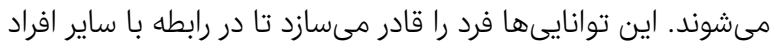

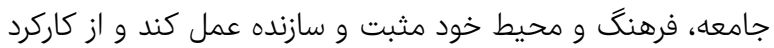

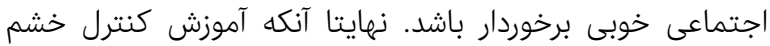

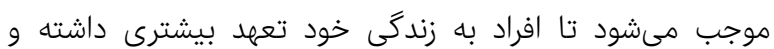

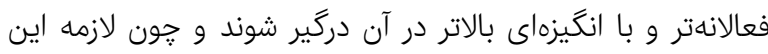

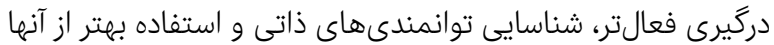

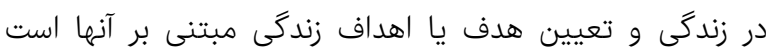

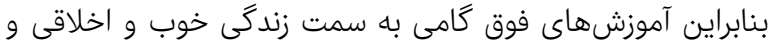

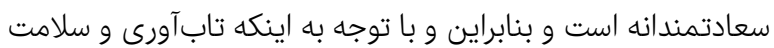
عمومى فرد در بهبود كاركرد وى تاثير به سزايى دارد، آموزش كنترل 
اثريخشى آموزش كنترل خشم بر تابآورى، شادكامى و سلامت عمومى در فرزندان يسر جانبازان سي relationship of mindfulness to resilience in university students. J Fundam Ment Health. 2016;18(6):586-600. [Persian]

19- Rahimi S, Borjali A, Sohrabi F. Effectiveness of positive psychology interventions on resiliency of female patients with multiple sclerosis. P0sitive Psychol. 2015;1(3):1-10. [Persian]

20- Hartley M. Examining the relationships between resilience, mental health, and academic persistence in undergraduate college students. J Am Coll Health. 2011;59(7):596-604.

21- Isanejad 0, Haydarian M. Effectiveness of resiliency training on quality of life and resiliency in prisoners of war. Iran J War Public Health. 2020;12(1):1-9. [Persian] 22- Connor M, Davidson R. Development of a new resilience scale: The connor - davidson resilience scale (CD- RISC). Depress Anxiety. 2003;18(2):76-82.

23- Peterson C, Park N, Seligman M. Orientation to happiness and life satisfaction: The full life versus the empty life. J Happiness Stud. 2005;6(1):25-41.

24- Sohrabi F, Ghafari Roshan F. Effectiveness of positive group pschotherapy on resiliency, happiness \& general health on women with a substance dependence spouses. Positive Psychol Res. 2016;2(1):45-31. [Persian]

25- Taghavi M. The normalization of general health questionnaire for Shiraz University Students (GHQ-28). Daneshvar Raftar. 2008;15(28):1-12. [ Persian]

26- Taghavi M. Validity and Reliability of General Health Questionnaire (GHQ). J Psychol. 2001;5(4):381-98. [Persian]

27- Khodabandehli Y. Self-reflection, a pursuit of happiness. J ROOYESH-E- RAVANSHENASI. 2015;3(4):111-30. [Persian]

28-Wheatley A, Murrihy R, Kessel J, Wuthrich V, Remond L, Tuqiri R. Aggression management trainging for youth in behavior schools. Youth Stud Aust. 2009;28(1):28-38.

29- Johnson JR, Emmons HC, Rivard RL, Griffin KH, Dusek JA. Resikience training: A Pilot study of a mindfulnessbased program with depressed healthcare professionals. Explore. 2015;11(6):433-44.

30- Kasir S, Hoseinimehr M, Aghilirad S, Sharhani M. Investigating the effectiveness of resilient curriculum training on reducing academic burnout among secondary high school students. Rooyesh-e-Ravanshenasi. 2020;8(12):39-49. [Persian]

31- Kobayashi LC, Wardle J, von Wagner C. Internet use, social engagement and health literacy decline during ageing in a longitudinal cohort of older English adults. J Epidemiol Community Health. 2015;69:278-83.

32- Ganji B, Tavakoli S. Surveying the relationship between psychological capital and academic resiliency with internet addiction of students. Educ Strategy Med Sci. 2018;11(1):102-07. [Persian]

33- Fergus S, Zimmerman A. Adolscent resilience: A framework for understanding healthy development in the face of risk. Annu Rev Public Health. 2015;26(1):399-419. 34- Werner EE. Resilience in development. Curr Dir Psychol Sci. 1995;4(3):81-5.

35- Loh JM, Schutte NS, Thorsteinsson EB. Be happy: The role of resilience between characteristic affect and symptoms of depression. J Happiness Stud. 2014;15(5):1125-38.

36- Velten J, Bieda A, Scholten S. Lifestyle choices and mental health: A longitudinal survey with German and Chinese students. BMC Public Health. 2018;18(1):632. 37-Shokoohi-Yekta M, Akbari Zardkhaneh S, Mahmoodi veterans and non-veterans. J Mil Med. 2016;17 (4):26572. [Persian]

2- Ghasemiyani B, Aghdasi A. Comparison of resilience, self-differentiation, and health-promoting lifestyle in children of the chemical warfare veterans, non-chemical veterans, prisoners of war and normal population. Iran J War Public Health. 2019;11(4):215-22. [Persian]

3- Rezapour Mirsaleh Y, Behjat Manesh A, Tavallaei S. Role of secondary post-traumatic stress disorder and resilience on academic motivation and performance of veterans' student children. Iran J War Public Health. 2016;8(4):225-33. [Persian]

4- Shokoohi Yekta M, Zamani N, Mahmoudi M, Pourkarimi J, Akbari Zardkhane S. Surveying the impact of cognitive behavioral intervention on high school students' control of anger. Daneshvar Raftar. 2015;21(14):61-70. [Persian] 5- Nasiri A, Khosravi S, Ghaderi Z, Vafaei T, Esmaeili M. The effectiveness of group training of problem solving to decrease identity crisis of girl teenagers (devotee's daughters). Iran J War Public Health. 2010;3(9):37-43. [Persian]

6- Sadri Damirchi B, Asadi Shishegaran S. Effectiveness of Social-Emotional Skills Program on Social ProblemSolving and Anger Control in Veterans' Children. Iran J War Public Health. 2016;8(4):209-15. [Persian]

7- Shirjang L, Mehryar A, Javidi H, Hosseini S. Effectiveness of social skills training on reducing symptoms of oppositional defiant disorder in children. Psychol Method Model. 2019;9(34):175-04. [Persian] 8- Meschke A, Laurie L, Patterson, Joan M. Resilience as a theoretical basis for substance abuse prevention. J Prim Prev. 2003;23(4):483-14.

9- Asgari M, Kazemi M, Alizadeh H. The effectiveness of training forgiveness therapy on controlling anger of students. J Psychol Achiev. 2016;22(1):155-74. [Persian] 10- Deming $\mathrm{M}$, Lochman, E. The relation of locus of control, Anger, and impulsivity to boys' aggressive behavior. Behav Disord. 2008;33(2):108-19.

11- Eftekhari A, Tumer A, Larimer M. Anger expression, coping, and substance use in adolescent offenders. Addict Bihav. 2004;29(5):1001-23.

12- Amidi Mazaheri M, Karbasi M. General mental health and aggression in female prisoners in Isfahan. Health Educ Health Promot. 2015;3(4):15-26.

13- Rasouli F. The impact of anger control training on resiliency in adolescents with addiction preparation. J Res Addict. 2011;16(4):24-7. [Persian]

14- Samadi Z, Eghlimi E, Memarbashi A, Armand A. The relationship between empowerment and resilience against cultural aggression among male high school students in Ferdows. Sixth International Conference on Psychology and Social Sciences. Tehran: Civilica; 2019. [Persian]

15- RavanShadi N. The Relationship between psychological well-being, resilience, and religious attitude with quality of life in students of Shahid Chamran University of Ahvaz [Dissertation]. Ahvaz: Shahid Chamran University of Ahvaz; 2015. [Persian]

16- Sadri Damirchi E, Bashorpoor S, Ramezani S, Karimanpour G. Effectiveness of resilience training on anger control and psychological well-being in impulsive students. J Sch Psycol. 2018;6(4):120-39. [Persian] 17- Shameli R, Hasani F. The effectiveness of reality therapy on resilience in mothers with children afflicted by cancer. Andishe va Raftar. 2017; 11(43): 77-87. [Persian] 18- Sedighi Erfeei F, Namaki Bidgoli Z. Examining the 
AF ميرزا حسن حسينى و همكاران AF

among heart disease patients after bypass surgery. Clin Psycol Stud. 2016;1(1):62-76. [Persian]

39- Oraki M, Amir Abadi, M, Heidari S. Study of relation between life quality and anger indices with mental health in Ostomy Patients of Tehran. Health Psycol. 2015;4(16):31-42. [Persian]
M, Dashti D. Efficacy of anger management training on hostility and well- being of parents. Knowl Res Appl Psychol. 2018;19(2):44-53. [Persian]

38- Bayrami M, Nemati Sogolitappeh F, Razmi S. Effectiveness of anger management and relaxation training on decreasing anxiety, depression and anger 